\title{
УДЕРЖАНИЕ ПОДРЯДЧИКОМ ИМУЩЕСТВА ЗАКАЗЧИКА И РЕЗУЛЬТАТА РАБОТ, КЛАССИФИКАЦИЯ ОБЪЕКТОВ УДЕРЖАНИЯ
}

Аннотация: В статье рассматриваются основные особенности удержания имущества заказчика и результата работ, их теоретические и практические аспекты. Предметом исследования явились правовые нормы, регламентирующие порядок удержания, научные труды отечественных циивилистов, а также материаль правоприменительной практики. В результате проведенного исследования, автором предлагается классификация объектов удержания. После чего каждый из объектов удержания рассматривается в отдельности. Освещаются проблемы и особенности, связанные с реализацией на практике прав на удержание. Особое внимание уделяется проблеме удержания результата работ, являющегося недвижимым имуществом. Методологическую основу исследования составил диалектический метод познания. В работе также использованы общенаучные и частноправовые методы исследования, такие как сравнительно-правовой, формально-юридический и др. В результате проведенного исследования, можно сделать вывод, что в настоящее время реализовать на практике право на удержание не так то просто, особенно если объектом удержания является недвижимая вещьь. Об этом свидетельствует неоднозначная и противоречивая правоприменительная практика, примеры из которой приведены в статье. Таким образом, чтобы на практике осуществить право на удержание таких спорных объектов, как результат строительных работ, незавершенных и реконструируемых работ, требуется серьезное закрепление на законодательном уровне порядка реализации прав на удержание подобных объектов.

Ключевые слова: Удержание, объект удержания, удержание имущества заказчика, удержание оборудования, удержание материалов, удержание результата работ, удержание недвижимой вещи, удержание незавериенных работ, удержание реконструируемых работ, классификация объектов удержания.

Abstract: This article reviews the key details of retention of customer's property and finished product, their theoretical and practical aspects. The subject of this research is the legal norms regulating the procedure of retention, scientific works of Russian civilists, as well as materials from legal precedent. As a result of the conducted research, the author offers classification of the objects of retention and provides a detailed review of each object individually. Attention is given to the problems related to exercising the right to retention, especially the problem of retaining a finished product represented by an object of real estate. The author concludes that at this time it is difficult to exercise the right to retain objects of real estate. This fact is confirmed by the ambiguous and controversial legal precedent, examples of which are offered in this article. Thus, in order to exercise the right to retention of such disputable objects as a result of construction work, unfinished and renovation projects, the procedure of exercising the right to retention of such objects should be established on the legislative level.

Keywords: Retention, Object of retention, Retention of customer's property, Retention of equipment, Retention of materials, Retention of finished product, Retention of real estate, Retention of unfinished work, Retention of renovation work, Classification of objects of retention.

соответствии со статьей 712 ГК РФ «при неисполнении заказчиком обязанности уплатить установленную цену либо иную сумму, причитающуюся подрядчику в связи с выполнением договора подряда, подрядчик имеет право на удержание в соответствии со статьями 359 и 360 ГК РФ результата работ, а также принадлежащих заказчику оборудования, переданной для переработки (обработки) вещи, остатка неиспользованного материала и другого оказавшегося у него имущества заказчика до уплаты заказчиком соответствующих сумм». [1]

Итак, согласно статье 712 ГК РФ объектом удержания может выступать как результат работ, так и при- надлежащее заказчику оборудование, переданная для переработки (обработки) вещь, остаток неиспользованного материала и другого оказавшегося у подрядчика имущества заказчика.

При этом как отмечает Е.А. Суханов, «предметом права удержания может быть только вещь, которая является собственностью должника (или принадлежит ему на ином титуле), то есть чужая для кредитора вещь. Объектом удержания не может быть собственная вещь ретентора, подлежащая передаче должнику (например, вещь, принадлежащая продавцу, в случае просрочки платежа, допущенной покупателем вещи), поскольку 
DOI: $10.7256 / 1811-9018.2015 .6 .15443$

При цитировании этой статьи сноска на dоі обязательна

\section{Право и политика 6 (186) 2015}

абсурдно само предположение, что собственник вещи должен получить удовлетворение своих денежных требований за счет стоимости своей вещи. Поэтому «удержание» собственной вещи может рассматриваться исключительно как предусмотренная п. 2 ст. 328 ГК РФ форма приостановления исполнения обязательства или отказа от его исполнения». [2]

С учетом вышесказанного, объекты удержания из договора подряда предлагается классифицировать следующим образом:

Таблицча №1 «Классификация объектов удержания»

\section{1. Удержание оборудования, переданного для переработки (обработки) вещи}

Так, для переработки (обработки) вещи заказчик может передать подрядчику определенное оборудование, которое и будет являться объектом удержания.

Необходимо отметить, что на практике встречаются случаи подобного удержания. Например, в одном из таких случаев, заказчик передал подрядчику в безвозмездное целевое временное пользование оборудование, необходимое

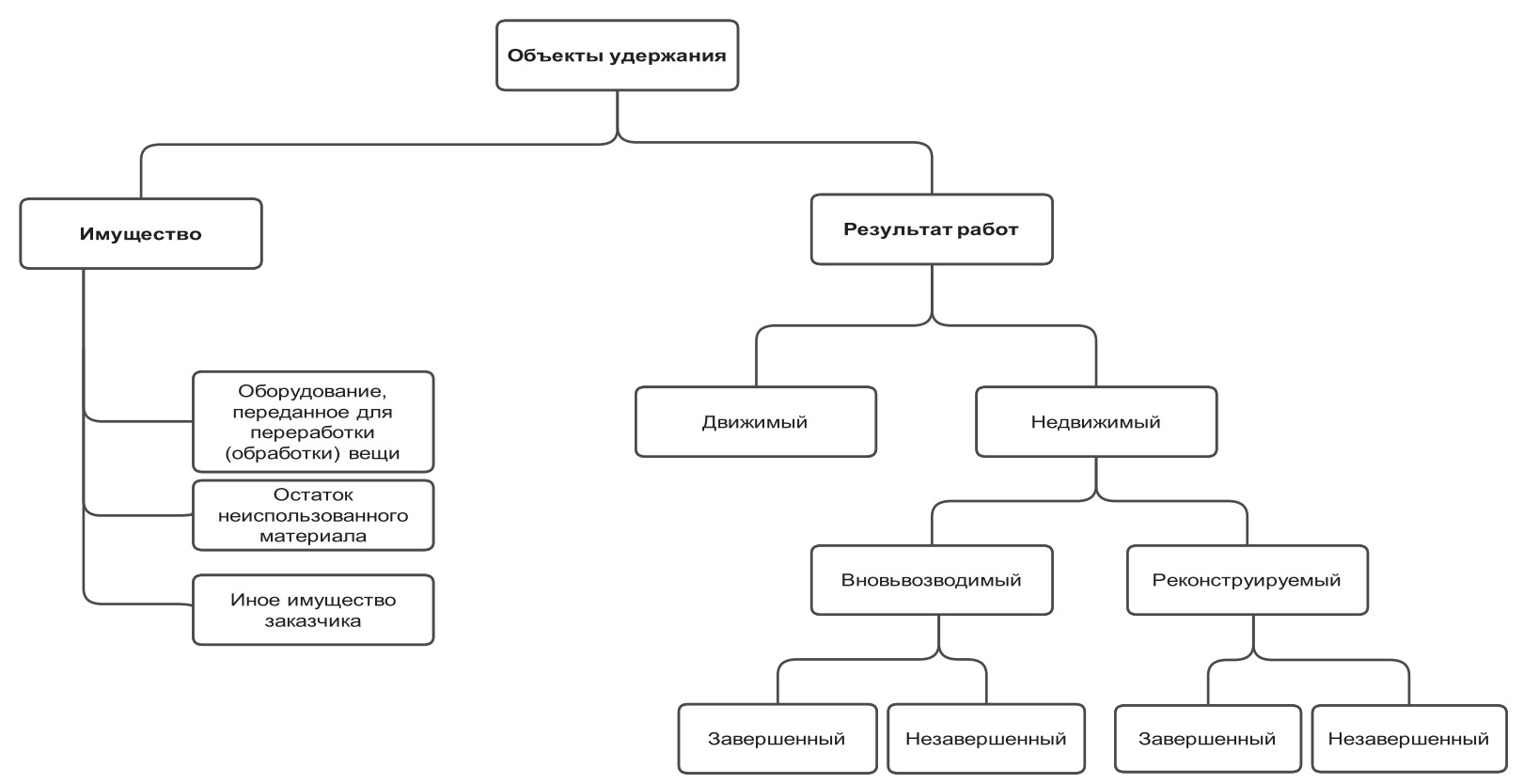

Таким образом, как следует из Таблицы № 1 «Классификация объектов удержания», объекты удержания подразделяются на две основные группы, первая - это имущество, принадлежащее заказчику, вторая - это результат работ.

Для начала рассмотрим более подробно первую группу объектов удержания и уделим особое внимание двум основным объектам удержания - это оборудование, переданное для переработки (обработки) вещи и остаток неиспользованного материала.

\section{1.Удержание имущества заказчика}

Итак, имущество заказчика можно подразделить на оборудование, переданное для переработки (обработки) вещи, остаток неиспользованного материала и иное имущество заказчика. При этом удержание подрядчиком имущества заказчика, как будет видно ниже, является наиболее доступным и реализуемым на практике. для производства кассовых боксов и иного торгового оборудования. Уклонение подрядчика от возврата заказчику всего переданного оборудования явилось основанием для обращения заказчика в суд. В соответствии с Определением ВАС РФ от 24.01.2011 N BAC-18406/10 по делу N A36-1/2010: «...Отклоняя довод заявителя о том, что оборудование удерживалось им по основаниям, предусмотренным статьей 359 Гражданского кодекса Российской Федерации, суд кассационной инстанциии пришел к выводу, что такое удержание возможно и правомерно, поскольку у ООО «Интер ТрейдШоп» имеласьзадолженность по оплате выполненных работп перед подрядчиком. Однако, во-первых, судами установлен факт удержания имущества, стоимость которого существенно превыниет размер долга, во-вторых, ответчик не обратился с иском об обращении взыскания на удерживаемое имущество в порядке статьи 360 Гражданского кодекса Российской Федерации...». [3]

Таким образом, суд не оспаривает возможность удержания переданного оборудования, но при этом 
указывает на то, что должна быть соблюдена соразмерность стоимости удерживаемого имущества нарушению и соблюден судебный порядок взыскания на удерживаемое имущество.

\section{2. Удержание остатка неиспользованного материала}

Что касается удержания материалов, предоставленных заказчиком, то по общему правилу, содержащемуся в пункте первом статьи 704 ГК РФ, «если иное не предусмотрено договором подряда, работа выполняется иждивением подрядчика - из его материалов, его силами и средствами». [4]

Аналогичная ситуация обстоит со строительным подрядом, где согласно пункту первому статьи 745 ГК РФ «обязанность по обеспечению строительства материалами, в том числе деталями и конструкциями, или оборудованием несет подрядчик, если договором строительного подряда не предусмотрено, что обеспечение строительства в целом или в определенной части осуществляет заказчик». [5]

Тем не менее, встречаются случаи, когда заказчик предоставляет подрядчику необходимые для выполнения работ материалы. В этом случае подрядчик выполняет работы, руководствуясь статьей 713 ГК РФ, и имеет право на удержание предоставленных заказчиком материалов, которые будут являться в данном случае объектами удержания.

Таким образом, с учетом вышесказанного, не всегда у подрядчика может оказаться во владении имущество заказчика, будь то оборудование, переданное для переработки (обработки) вещи, либо же давальческий материал. В этом случае наиболее актуальным становится право подрядчика на удержание результата работ.

В продолжение раскрытия темы статьи рассмотрим вторую группу объектов удержания - результат работ и уделим больше внимания недвижимому результату работ.

\section{2. Удержание результата работ}

Так, согласно Таблице №1 «Классификация объектов удержания» результат работ может быть как движимым, так и недвижимым, в свою очередь недвижимый результат подразделяется на вновьвозводимый и реконструируемый, при этом оба этих результата работ могут быть как завершенными, так и незавершенными.

Если порядок реализации права на удержание движимого результата работ можно отнести по аналогии к порядку реализации права на удержание оборудования, материалов и прочего имущества заказчика, то с реализацией права подрядчика на удержание недвижимого результата работ возникает огромное количество споров и дискуссий. Поэтому остановимся более подробно на недвижимом результате работ, как объекте удержания.

\section{1. Удержание результата работ, являющегося недвижимым имуществом}

Рассмотрим некоторых сторонников и противников возможности удержания недвижимой вещи.

Так, по мнению Е.А. Суханова: «не исключено удержание недвижимой вещи (например, арендованного здания), причем право ее удержания возникает независимо от его государственной регистрации». [6]

Аналогичного мнения придерживаются Н.В. Южанин и В.А. Рыбаков, которые считают, что «применение удержания к недвижимости возможно в силу существующего законодательства и государственной регистрации такой сделки не требуется. Считаем в полной мере возможным применение удержания как к движимым вещам, так и к недвижимым, и никаких законодательных поправок в этом аспекте не нужно, напротив, законодательная поправка в ст. 359 ГК РФ удержания только движимого имущества создала бы массу противоречий». [7]

Противоположной точки зрения придерживаются М.И. Брагинский и В.В. Витрянский, которые отмечают: «вместе с тем осуществление кредитором права удержания с последующим обращением взыскания на удерживаемое имущество представляет собой гражданско - правовую сделку. Сделки с землей и другим недвижимым имуществом подлежат обязательной государственной регистрации (ст. 164 ГК), что противоречит существу правоотношений, возникающих при осуществлении кредитором права удержания имущества. Да и ст. 131 ГК, а также другие законы не включают право удержания в перечень обременений недвижимого имущества, подлежащих государственной регистрации. На наш взгляд, изложенные обстоятельства не позволяют включать в круг вещей, которые могут служить предметом удержания, недвижимое имущество». [8]

Однако, наиболее верной представляется первая позиция, говорящая о возможности удержания недвижимого результата работ независимо от государственной регистрации прав на него, обоснование данного вывода изложено ниже.

Вначале необходимо дать определение понятию недвижимого имущества, которое закреплено в статье 1 Федерального закона от 21.07.1997 N 122-Ф3 «О государственной регистрации прав на недвижимое имущество и сделок с ним», а именно: «недвижимое имущество (недвижимость), права на которое подлежат 
DOI: 10.7256/1811-9018.2015.6.15443

При цитировании этой статьи сноска на доі обязательна

\section{Право и политика $6(186) \cdot 2015$}

государственной регистрации в соответствии с настоящим Федеральным законом, - земельные участки, участки недр и все объекты, которые связаны с землей так, что их перемещение без несоразмерного ущерба их назначению невозможно, в том числе здания, сооружения, жилые и нежилые помещения, предприятия как имущественные комплексы». [9]

Таким образом, результатом работ в нашем случае будет являться здание, сооружение или помещение, определения данных понятий приведены в Федеральном законе от 30.12.2009 N 384-Ф3 «Технический регламент о безопасности зданий и сооружений». Так, согласно подпунктам 6, 14 и 23 пункта 2 статьи 2 указанного Ф3 «здание - результат строительства, представляющий собой объемную строительную систему, имеющую надземную и (или) подземную части, включающую в себя помещения, сети инженерно-технического обеспечения и системы инженерно-технического обеспечения и предназначенную для проживания и (или) деятельности людей, размещения производства, хранения продукции или содержания животных; помещение - часть объема здания или сооружения, имеющая определенное назначение и ограниченная строительными конструкциями; сооружение - результат строительства, представляющий собой объемную, плоскостную или линейную строительную систему, имеющую наземную, надземную и (или) подземную части, состоящую из несущих, а в отдельных случаях и ограждающих строительных конструкций и предназначенную для выполнения производственных процессов различного вида, хранения продукции, временного пребывания людей, перемещения людей и грузов». [10]

Следует так же отметить, что результат работ возникает в ходе реализации договора строительного подряда, если только объект не строится заказчиком самостоятельно, собственными силами и средствами.

Так, согласно статье 740 ГК РФ по договору строительного подряда подрядчик обязуется в установленный договором срок построить по заданию заказчика определенный объект либо выполнить иные строительные работы, а заказчик обязуется создать подрядчику необходимые условия для выполнения работ, принять их результат и уплатить обусловленную цену.

Так как одним из обязательных условий для удержания является наличие у заказчика задолженности по оплате выполненных работ, которая может возникнуть только после приемки результата работ, то можно сделать вывод, что результат работ должен быть передан заказчику.

При этом, если результат работ заказчику не передан и заказчик при этом уклоняется от его приемки, в этом случае, подрядчик вправе воспользоваться своим правом, согласно пункту 6 статьи 720 ГК РФ, по истечении месяца со дня, когда согласно договору результат работы должен был быть передан заказчику, и при условии последующего двукратного предупреждения заказчика продать результат работы, а вырученную сумму, за вычетом всех причитающихся подрядчику платежей, внести на имя заказчика в депозит в порядке, предусмотренном статьей 327 ГК РФ.

Еще одним обязательным условием для удержания является то, что результат работ должен принадлежать заказчику. Здесь необходимо отметить, что с приемкой результата работ, у заказчика возникает не только обязанность по его оплате, как было сказано выше, но и возникают соответствующие права на результат работ. Заказчик уже на этом этапе может владеть, пользоваться и распоряжаться результатом работ, например, он может изменить назначение объекта и полностью перестроить его под новое назначение и только потом зарегистрировать права на него как на объект недвижимого имущества.

Так же следует обратить внимание на то, что результат работ передается заказчику по соответствующему акту сдачи-приемки результата работ. Так, согласно пункту 4 статьи 753 ГК РФ «сдача результата работ подрядчиком и приемка его заказчиком оформляются актом, подписанным обеими сторонами». [11]

И здесь нельзя не согласиться с Ершовым О.Г., который считает, что «подписание акта позволяет установить момент возникновения вещного права у заказчика на результат выполненных работ. При проектировании это момент возникновения права собственности на изготовленную проектно-сметную документацию или материалы инженерных изысканий. При строительном подряде и долевом строительстве это иное вещное право, поскольку право собственности у заказчика или участника долевого строительства на результат работ в виде объекта недвижимости возникает с момента государственной регистрации». [12]

Кроме того, следует отметить, что с подписанием акта сдачи-приемки результата работ стоимость имущества учитывается на балансе заказчика, из чего вытекают имущественные права заказчика на этот результат работ, а так же связанные с ним обязанности. Так, согласно статье 741 ГК РФ после приемки объекта заказчиком, к нему переходит риск случайной гибели или случайного повреждения объекта строительства.

Более того, если заказчик не примет у подрядчика результат работ, то создаваемый объект даже пусть на принадлежащем заказчику земельном участке не может быть расценен как полученный на законных основания. 
В результате того, что заказчик не понес фактических расходов на его создание, полученный результат работ будет являться ничем иным как неосновательным обогащением, согласно статье 1102 ГК РФ.

Таким образом, у заказчика возникает право на результат работ с момента приемки по акту сдачи-приемки результата работ. После чего, заказчик уже вправе владеть, пользоваться и распоряжаться результатом работ.

С учетом вышесказанного можно сделать вывод, что недвижимое имущество это результат работ, созданный в ходе строительства по договору строительного подряда. А значит, в силу статьи 712 ГК РФ данный результат работ может являться объектом удержания. При этом независимо от государственной регистрации прав на него, так как в данном случае важно установление факта принадлежности результата работ заказчику, а принадлежит результат работ заказчику с момента его приемки.

Однако, судебная практика порой крайне противоречива в поставленном вопросе, и как с одной стороны существует практика, говорящая о том, что не зарегистрированный объект удерживать нельзя.

Например, в Постановлении Четырнадцатого арбитражного апелляционного суда от 06.05.2013 по делу N А66-8606/2012 «Объект недвижимости, который удерживается истиом, представляет собой незаконченный строительством 16-квартирный жилой дом со встроенными офисными помещениями. В настоящее время по строительству дома выполнено порядка $37 \%$ строительных работ. Право на удержание подрядчиком результата незавершенной работы гражданским законодательством не предусмотрено. В силу статей 130, 219 Гражданского кодекса Российской Федераиии незавершенное строительство является недвижимым имуществом, право собственности на которое возникает с момента государственной регистрации... ... Поскольку право собственности на спорный объект незавершенного строительства не зарегистрировано и собственник объекта незавершенного строительства в установленном порядке не определен, обращение взыскания на такое имущество путем его реализаиии также невозможно. Довод о правомерности удержания подрядчиком результата подрядных работ также подлежит отклонению». [13]

Так и с другой стороны встречается практика, говорящая о том, что в случае регистрации права за заказчиком, подрядчик уже не вправе удерживать объект.

Например, в Постановлении Восемнадцатого арбитражного апелляционного суда от 24.12.2009 N 18АП11322/2009 по делу N A76-15882/2009 «Удержание рассматривается как право кредитора, которое возника- ет при наличии юридического факта - неисполнения или ненадлежащего исполнения обязательства должника по оплате подлежащей передачи ему вещи. Принимая во внимание ссылку ответчика о применении удержания в качестве обеспечительной меры, следует учитывать, кому принадлежит удерживаемая недвижимая вещь. Поскольку в данном случае право собственности было зарегистрировано за заказчиком, подрядчик был не вправе удерживать вещь, право собственности на которую было зарегистрировано Заказчиком. В данной ситуачии Генподрядчик мог действовать только исходя из статьи 328 Гражданского кодекса, в соответствии с которой в случае неисполнения стороной своего обязательства, другая сторона, на которой лежит встречное исполнение, вправе такое исполнение приостановить либо отказаться от исполнения и потребовать возмещения убытков». [14]

Таким образом, в одном случае суд отказал по причине того, что право собственности не было зарегистрировано и собственник имущества не установлен, при этом во втором случае суд отказал по причине того, что собственник установлен и зарегистрировал свое право на имущество.

В вышеуказанной противоречивой судебной практике больше всего страдает подрядчик, который сталкивается с невозможностью на практике реализовать свое право на удержание.

При этом хуже дело обстоит с результатами незавершенных работ и результатами реконструируемых работ. По причине того, что данные объекты не закреплены в статье 712 ГК РФ, судами они в качестве объектов удержания вообще не признаются. К примеру, из Постановления Двенадцатого арбитражного апелляционного суда от 25.01.2008 по делу N A-57-15861/07-39 «как следует из положения статьи 712 ГК РФ, объектом удержания может являться результат работ. $B$ соответствии с указанной нормой, при неисполнении заказчиком обязанности по уплате установленной иены, подрядчик вправе удерживать результат работ (cm. 359, 360 ГК РФ). Право на удержание подрядчиком результата незавершенной работы - гражданским законодательством не предусмотрено». [15] А так же из Постановления Пятнадцатого арбитражного апелляционного суда от 21.08.2013 N 15АП-10619/2013 по делу N A53-5141/2013 «следует отметить, что Арбитражная практика исходит из того, что удержание подрядчиком результата незавершенной работы со ссылкой на ст. 712 ГК РФ является неправомерным. В соответствии с указанной нормой, при неисполнении заказчиком обязанности по уплате установленной 
DOI: $10.7256 / 1811-9018.2015 .6 .15443$

При цитировании этой статьи сноска на dоі обязательна

\section{Право и политика $6(186) \cdot 2015$}

ичены, подрядчик вправе удерживать результат работ. Право на удержание подрядчиком результата незавершенной работы гражданским законодательством не предусмотрено. Результат незавершенной работь нельзя рассматривать в качестве вещчи, подлежащей передаче должнику (заказчику), по смыслу п. 1 cm. 359 ГК РФ. Аналогичная правовая позиция изложена в Постановлении Федерального Арбитражного суда Уральского округа по делу N Ф09-1209/04». [16]
Таким образом, все поименованные в Таблице № 1 объекты удержания могут и должны иметь возможность применяться на практике. Однако, для спорных объектов, таких как удержание результата строительных работ, все таки требуется законодательное закрепление порядка реализации подрядчиком права на их удержание, что позволит подрядчику воспользоваться таким, как видится, действенным инструментом и осуществить свои права.

\section{Библиография:}

1. Гражданский кодекс Российской Федерации (часть вторая) от 26.01.1996 N 14-Ф3 (ред. от 22.12.2014) // Собрание законодательства РФ, 29.01.1996, N 5, ст. 410

2. Суханов Е.А. Российское гражданское право: Учебник: В 2 т. Т. ІІ: Обязательственное право-2-е изд., стереотип. - М.: Статут, 2011. - С. 129

3. Определение ВАС РФ от 24.01.2011 N ВАС-18406/10 по делу N А36-1/2010 // Архив ВАС РФ

4. Гражданский кодекс Российской Федерации (часть вторая) от 26.01.1996 N 14-Ф3 (ред. от 22.12.2014) // Собрание законодательства РФ, 29.01.1996, N 5, ст. 410

5. Гражданский кодекс Российской Федерации (часть вторая) от 26.01.1996 N 14-Ф3 (ред. от 22.12.2014) // Собрание законодательства РФ, 29.01.1996, N 5, ст. 410

6. Суханов Е.А. Российское гражданское право: Учебник: В 2 т. Т. II: Обязательственное право-2-е изд., стереотип. - М.: Статут, 2011. - С. 129

7. Южанин Н.В., Рыбаков В.А. Удержание как способ обеспечения исполнения обязательств // «Арбитражный и гражданский процесс», 2002, № 2

8. Более подробно см.: Брагинский М.И., Витрянский В.В. Договорное право. Общие положения. 3-е изд., стереотипное. М.: Статут, 2001. Кн. 1. 848 с.

9. Федеральный закон от 21.07.1997 N 122-Ф3 (ред. от 29.12.2014) «О государственной регистрации прав на недвижимое имущество и сделок с ним» (с изм. и доп., вступ. в силу с 01.03.2015) // Собрание законодательства РФ, 28.07.1997, N 30, ст. 3594

10. Федеральный закон от 30.12.2009 N 384-Ф3 (ред. от 02.07.2013) «Технический регламент о безопасности зданий и сооружений» // Собрание законодательства РФ, 04.01.2010, N 1, ст. 5

11. Гражданский кодекс Российской Федерации (часть вторая) от 26.01.1996 N 14-Ф3 (ред. от 22.12.2014) // Собрание законодательства РФ, 29.01.1996, N 5, ст. 410

12. Ершов О.Г. Подписание акта приемки результата строительных работ: сделка, сделкоподобные или фактические действия? // Право и экономика, 2012, N 7

13. Постановление Четырнадцатого арбитражного апелляционного суда от 06.05.2013 по делу N A66-8606/2012 // Архив Четырнадцатого арбитражного апелляционного суда

14. Постановление Восемнадцатого арбитражного апелляционного суда от 24.12.2009 N 18АП-11322/2009 по делу N A7615882/2009 // Архив Восемнадцатого арбитражного апелляционного суда

15. Постановление Двенадцатого арбитражного апелляционного суда от 25.01.2008 по делу N A-57-15861/07-39 // Архив Двенадцатого арбитражного апелляционного суда

16. Постановление Пятнадцатого арбитражного апелляционного суда от 21.08.2013 N 15АП-10619/2013 по делу N A53-5141/2013 // Архив Пятнадцатого арбитражного апелляционного суда

\section{References (transliterated):}

1. Sukhanov E.A. Rossiiskoe grazhdanskoe pravo: Uchebnik: V 2 t. T. II: Obyazatel'stvennoe pravo-2-e izd., stereotip. - M.: Statut, 2011. - S. 129

2. Sukhanov E.A. Rossiiskoe grazhdanskoe pravo: Uchebnik: V 2 t. T. II: Obyazatel'stvennoe pravo-2-e izd., stereotip. - M.: Statut, 2011. - S. 129

3. Yuzhanin N.V., Rybakov V.A. Uderzhanie kak sposob obespecheniya ispolneniya obyazatel'stv // "Arbitrazhnyi i grazhdanskii protsess”, 2002, № 2

4. Braginskii M.I., Vitryanskii V.V. Dogovornoe pravo. Obshchie polozheniya. 3-e izd., stereotipnoe. M.: Statut, 2001. Kn. 1. 848 s.

5. Ershov O.G. Podpisanie akta priemki rezul'tata stroitel'nykh rabot: sdelka, sdelkopodobnye ili fakticheskie deistviya? // Pravo i ekonomika, 2012, N 7 